\title{
Community development in urban Guangzhou since 1980: a social sustainability perspective
}

\author{
Zongcai Wei ${ }^{1,2}$, Bo Wang ${ }^{3}$, Tingting Chen ${ }^{4, *}$, Yunqi $\operatorname{Lin}^{5}$ \\ 1 School of Architecture, State Key Laboratory of Subtropical Building Science, South China \\ University of Technology \\ 2 Department of Urban Planning and Design, The University of Hong Kong \\ 3 Department of Geography, The University of Hong Kong \\ 4 School of Geography and Planning, Sun Yat-Sen University, Urbanization Institute of Sun Yat- \\ Sen University \\ 5 Department of Urban Planning, Southeast University \\ * Corresponding Author, Email: cindychenhku@gmail.com
}

Received: March 8, 2016; Accepted: June 4, 2016

Key words: Community development, Work-unit compounds, Gated communities,

Housing marketization reform, Social sustainability, Guangzhou

\begin{abstract}
Following the worldwide trend of housing privatization, housing marketization reform was conducted by the Chinese government to tackle the giant housing shortage. However, since then, community development based on the relatively homogeneous work-unit compound has experienced radical transformations. The residential space in urban China has become more complicated, fragmented and segregated, and gated communities become the dominant component. However, are the new types of housing estates that have emerged after the reform more socially sustainable than the former? What are the typical issues of these housing estates from the perspective of social sustainability? Theoretically, the impact of housing marketization reform in China on the community level has received relatively less attention. Moreover, little research on the social sustainability has been conducted for cities and communities in mainland China. This paper aims to explore evolving housing estates and their social sustainability in China, using a case of Guangzhou, which enriches the international debates on social sustainability at the community level. The paper concludes that it is challenging to identify which types of communities are more socially sustainable, owing to the comprehensive nature of social sustainability. However, one type of community may have advantage over others in some aspects. The living environment of gated communities is indeed better than work-unit neighborhoods, while the social relations within the work-unit compounds are more harmonious.
\end{abstract}

\section{INTRODUCTION}

Housing is an important and common issue of peoples' livelihoods in the government agenda globally. Following the worldwide trend of housing privatization, the marketization of public housing has been implemented in China since 1980, which has been considered as some of the most important elements of economic reform (Lee, 2000; Logan, J. R. \& Bian, 1993; Wang \& Murie, 1996; Wu, 1996; Zhou \& Logan, 1996). However, compared with other countries in the world, housing development based on the relatively 
homogeneous work-unit society in urban China has experienced more radical transformations due to the tremendous transition from the Socialist Planned Economy to the Socialist Market Economy. The residential space has become more complicated, fragmented and segregated, and gated communities become the dominant component.

The housing marketization reform in China has been discussed by many scholars. Gao (1990) compared the different roles of developers and housing consumers in the development process of the Chinese housing market, highlighting the relationships between markets and affordable housing according to the targeted coverage of housing market reforms. Wu (1996) pointed out that the state work-units played a critical role in the changes of public-sector housing in China. Recently, scholars begun to rethink the drawbacks of this housing reform. Wang and Murie (1996) contend that housing reform in Chinese cities has been considered a significant change to the socialist urban system, while the housing market and the socialist status in China still remain in a transitional phase with inequalities. Lee (2000) argues that the reform process has generally neglected its impact on issues such as inequality and distributive justice. (Huang, 2005) holds that a relatively homogeneous society characterized by work-unit compounds in socialist China has been evolving into one with significant stratification and segregation, with the implementation of housing marketization policy. Chen, Chen, and Liu (2008) also point out how housing marketization has aggravated housing and income inequality should be promulgated. Ye, Song, and Tian (2010) consider the effect of social housing policies since the housing marketization, particularly on remedying the emergent weaknesses during this process. The extant literature mainly concentrates the housing marketization process and its effects on the city or country level. Nevertheless, the impact of housing marketization reform on the community level has received less attention.

Sustainable development has aroused extensive attention globally, both academic and political, since the late 1980s, coinciding with the publication of the so-called Brundtland Report 'Our Common Future' in 1987. This notion has become increasingly influential on planning, housing and urban policy worldwide. Although the social dimension of sustainability is widely accepted, there is no consensus on the definition of social sustainability (Bramley \& Power, 2009; Colantonio, 2010; Dempsey et al., 2011), since this concept is currently being approached from diverging research perspectives, and another reason is the difficulty of assessing the intangible nature of social aspects of development (Colantonio, 2010). Therefore, there are even less investigations on social sustainability at the community level. However, little research has been conducted for cities and communities in mainland China. There is a high demand to explore whether the current housing estates of the developing countries, especially in transitional urban China, are socially sustainable or not, and to what extent? Moreover, which are more socially sustainable among different types of housing estates?

In the following sections, the definition of social sustainability at the community level is first reviewed to establish an analytical framework for this study. Subsequently, the evolving processes of housing policy in China since 1980 are discussed in section three, with a special focus on Guangzhou. To present a wider picture of the multifunctional socio-spatial connotations of housing estates in urban China, the analytical framework is applied to investigate the typical characteristics and issues of two different types of urban enclaves from the perspective of social sustainability and to unpack their heterogeneities in the following sections. This study would 
enrich the international debates on social sustainability at the community level and aid in the creation of socially sustainable communities.

\section{SOCIAL SUSTAINABILITY: LITERATURE REVIEW}

Prior to evaluating the social sustainability of housing estates, it is indispensable to identify the definition of social sustainability at the community level. Social sustainability is an umbrella concept and there is no consensus on this concept. In addition, there is relatively limited literature focusing on social sustainability (Bramley \& Power, 2009). Moreover, it is a multi-dimensional concept with the underlying question 'what are the social goals of sustainable development?' (Dempsey et al., 2011).

Communities can be regarded as 'physically delimited spaces within urban settlements, bringing together residents and businesses who live and work in them, and organizations, from within or without, concerned with managing the people and building in the area' (Manzi et al., 2010). Some scholars believe community is a living organism. It grows, improves, deteriorates and changes over time. The elements that influence such change have become more complex as the society emerges (Wiesel, 2012). Community is also considered as one indispensable dimension which should be taken into account to define social sustainability (Pareja-Eastaway, 2012). The neighborhood unit is a physical design tool that provides opportunities for residents to interact with people and to develop sense of place and ownership (Lawhon, 2009).

Compared with the studies on social sustainability at the community level, there are more studies and practices in a broader and more comprehensive field: sustainable community, which mainly focuses on several key themes, including meeting the diverse needs of residents (Office of the Deputy Prime Minister, 2006; City of Vancouver (CoV), 2005; McKenzie, 2004; Raco, 2003), social interaction/social networks (City of Vancouver (CoV), 2005; Dempsey et al., 2011; Manzi et al., 2010), participation (Dempsey et al., 2011; McKenzie, 2004) and safety and security (Office of the Deputy Prime Minister, 2006; Dempsey et al., 2011); It is clear that these above definitions and principles of sustainable communities are human-orientated, emphasizing more on the social aspects, which mirrors the significant role of social pillars in sustainable development at the community level.

However, successful programs to deliver sustainable communities are delicate and applicable to local circumstances rather than trying to exhibit a 'pattern' that works elsewhere (Congreve, 2012). When we discuss the social sustainability of communities, the main components of social sustainability are basic needs, individual capacity and social capacity. Individual capabilities are linked to education, skills, health, values and leadership, while community capabilities stem from relationships, networks and norms facilitating collective action (Colantonio, 2010). It is obvious that sustainability of community concentrates more on the collective aspects of social life than on the individual ones. However, the basic needs should not be neglected. In addition, Chiu (2004) points out the social sustainability of housing should focus on both the people and the environment.

It can also be found that there is a common ground where the physical context is highlighted in the definition of social sustainability in both the 
urban context and housing context, indicating that there could be some relationships between the social sustainability and physical/environmental aspects. Therefore, social sustainability at the community level encompasses two dimensions in this study: the living environment for meeting the diverse needs of residents, which contains internal housing conditions, such as the adequacy of dwelling space, degree of self-containment and community facilities and related services; social relations within the community covers the involvement of the public or at least the stakeholders in the community activities, and in the formulation and implementation of housing policies.

\section{HOUSING REFORM IN CHINA SINCE 1980}

Since 1980, the housing system in China has undergone dramatic transformations from domination by public/collective ownership and administrative allocation to home-ownership and privatization after housing reform. Guangzhou is no exception. The transition from the traditional workunit system to the gated enclaves in the housing marketization process is achieved. There are three major stages.

\subsection{0 - 1997, housing reform experiments on marketization}

During the period from 1949 to the 1980s, the work-units owned by the government played a dominant role in the housing system. These types of housing estates were built and distributed to users by administrative means. However, a critical housing shortage was triggered due to the low efficiency of the social welfare-orientated housing system (Wang \& Murie, 1996). To satisfy the increasing demand for housing, China conducted several housing reform experiments following Deng Xiaoping's speeches on the direction for urban housing reform in 1978 and 1980, such as encouragement of the marketization of the housing sector. In 1991, a comprehensive housing reform strategy was issued by the State Council to reinforce the reform, primarily through varying housing prices in accordance with affordability in the mid-1990s. Increasingly, more work-unit compounds were transformed into commodity housing enclaves during this process. Guangzhou was not selected as one of the experimental cities in this reform wave owing to its essential economic role nationwide. Guangzhou initiated its housing reform in 1989 and accomplished this mission around 2000.

\section{2 $1998-$, deepening of urban housing system reform and the rise of gated communities}

In July 1998, to accelerate the pace of housing reform, the Central Government announced further intensified policy on the termination of the administrative distribution of housing and the gradual implementation of housing monetization. However, due to some complex difficulties in the implementation process, especially financial constraints and fragmented organization, this policy could not be set on the ground until January 2000. Even so, the progress of housing commercialization in Chinese cities has sped up and been accomplished.

Since the late 1990s, gated communities have become prevalent in urban China, classifying from luxury housing estates to ordinary commodity 
housing communities. Actually, the principle of 'gated community' is adopted by almost all the new-built commodity housing estates now (Miao, 2003). The expansion of gated communities developed by real estate developers has become intensive and property management companies have been introduced into community management in the process of market-based property development. The gated communities are constructed extensively in different locations in the cities, while the luxury gated communities are generally clustering into some scarce lots.

As a significant element of rapid urbanization, the construction of gated communities with a large proportion in the suburban areas has been experienced by many Chinese cities, and Guangzhou is a representative case. In Panyu district of southern Guangzhou, several major real estate developers, like Star River, Agile, Country Garden and so on, led an influential new towns' building movement on a super-large scale. All the implemented estates are gated communities, which occupy the cultivated land with a total number of approximately 17 square kilometers and generate massive negative influence on the sustainable development at the city level.

\section{SOCIAL SUSTAINABILITY OF WORK-UNIT COMPOUNDS IN GUANGZHOU}

Generally, work-unit refers to a special kind of workplace in the context of state socialism where the workplace becomes an extension of the state apparatus and undertakes the function of social organization ( $\mathrm{Wu}, 1996)$. Although the housing market reform was launched a few decades ago, the work-units are still functioning within the housing system (Huang, 2005). The construction of work-unit urban housing in China was mainly conducted by the government, and its provision, considered as one aspect of socialist welfare, is largely implemented and administrated through work units. Local governments put the achievement of greater, faster, better and more economical outcomes as their top priority, rather than the protection of the natural environment. Thus, there is no difference between the construction of work-unit compounds and the production of industrial products. In addition, all the work-unit compounds seemed quite similar, with a lack of local characteristics and environmentally friendly design. Considering the development intensity, compared with the low-rise dwellings of three or four storeys in the 1950s, the buildings in the 1980s grew higher, with six storeys (Zhang, Chai, \& Zhou, 2009), which promoted the rapid increase of building density and of the Plot Ratio of the housing estates. With the scarcity of the land quota for construction in the city proper, increasingly more large-scale work-unit communities were developed in the peri-urban area of the city.

Generally, the self-contained 'corporate-governed' unit is a typical characteristic of the socialist public housing system in China. Although great differences emerged in the scale and layout of the work-unit compounds nationwide, two fundamental function areas, including the working area and the living area, should be covered. The health, education and housing-related services are provided in the living area for the self-sufficiency of the workunit compounds, which makes residents easily able to access the daily goods and services within the communities.

However, the housing space of the work-unit compound was quite low, due to the scarcity of the housing resources. The per capita living space in the urban area had remained roughly 4 square meters since 1949, and rose to 
7.5 square meters in 1993 (Logan, R. et al., 1997). Nevertheless, the living condition of the residents was still very low due to the insufficient investment, and 20 percent of households still had less than six square meters of living space per capita (Logan, R. et al., 1997). Moreover, the building quality of multi-floor walk-ups in the work-unit compounds is relatively low ( $\mathrm{Wu}, 2010)$.

In Guangzhou, the 'Construction New Village', completed in 1953, was one of the first generation of workers' villages in China, which housed around 4,700 ordinary workers and their households. Similar to other workunit compounds, there were a health center, child-care center, food market, square and other essential services in this new village. Therefore, residents could easily go to work and get their daily necessities and services in an acceptable walking distance. Generally, the access to these kinds of workunit compounds is convenient, although several gates may be set up in the entrance.

\subsection{Friendly social relations}

As the basic social cells of urban China under the Socialist Planned Economic System, work-unit compounds were characterized with a wall or fence with several gates. Every work-unit compound had its own Communist Party branch, which was responsible for the daily operation of the work unit. There was also a set of committees attached to the Communist Party branch to organize the public activities or deal with specific problems (Howenstine, 1986). Taking 'Construction New Village' in Guangzhou as an example, a public security office was set up to maintain the social order and to provide security services against outsiders without reasonable reasons for entry.

Generally, work-unit represented a set of social, economic, political and spatial constrains on the lives of its members. As argued by Howenstine (1986), the social strength of the danwei group, or a work-unit, tended to reduce or minimize the number of contacts people had outside it. Thus, the work-unit had an overall repressing effect on the frequent social interaction with an outsider. However, tightening social networks was highly developed within the work-unit compounds and formed an important basis for social stability and social satisfaction. In the pre-reform era, the residents in the same work-unit compounds lived together in the apartments where social interaction was more intense, social cohesiveness more strong, and social inequality less pronounced than in the pre-socialist and post-socialist periods (Ma, 2002). The urban households enjoyed relatively equal income, education, medical treatment, and other social welfares.

The hierarchical structure was adopted by the work-unit system to regulate their members. All the workers and cadres in the work-unit compounds were incorporated into this hierarchical system in the Socialist Planned China. In large work-units, like the Guangzhou Iron \& Steel Group, which consisted of several organized sub-work-units, each sub-work-unit was responsible for organizing its workers and their dependents. This greatly promoted the solidarity of members in the same work group, and also made it easier to organize discussions for political study. Moreover, the regulation function of the work units also had other performances on their members. The six-day work cycle also restricted the time that members spent with external contact (Howenstine, 1986). Many measures, such as the weekend films, singing contests and sport contests, held by the work-units enabled their members to concentrate on their internal affairs. Thus, affiliation to the same workplace led to intensive interaction among residents $(\underline{\mathrm{Wu}, 2005})$. 


\subsection{Lower quality of the living environment}

China confronted a widespread severe housing shortage in the Socialist Planned period. According to the results of the housing census conducted in 1985 , the per capita living space in urban areas nationwide was only around 6.4 square meters, a very low living standard. Moreover, families living in self-contained housing only occupied 24 percent. To solve this, some residential blocks were designed for two or more families sharing one kitchen, toilet and bathroom. However, privacy could not be guaranteed. This principle was adopted not only by Guangzhou, but also by all cities in China. Although one or several doors might be installed in the entrance, the security verification was not very stringent, and the unprofessional property management was also a factor. For example, in most communities of Guangzhou, urban dwellers were not stopped because of no significant differences between the residents and outsiders. Thus, theoretically, these communities were gated, but not 'fortified' ( $\mathrm{Wu}, 2005)$.

In the initial stage, the work-unit compounds operated as full-fledged communities, functioning as a city within a city ( $\mathrm{Ma} \& \mathrm{Wu}, 2005)$, which could provide the clinics, childcare, primary education, restaurants, stores, heating services, transportation, and so on. On one hand, this "Chinese Work-unit Society" mode enabled residents easy access to their daily requirements without going outside, which facilitated to strengthen the social cohesion among the work-units. On the other hand, it also generated redundant construction of some housing-related facilities and severe waste of energy and resources. For example, although the work-unit compounds owned by the Guangdong Communist Party School was close to the "Construction New Village" in geographical location, the water infrastructure was constructed in this respective context of "selfsufficiency", other than sharing with its neighbor.

\section{SOCIAL SUSTAINABILITY OF GATE COMMUNITIES IN GUANGZHOU}

As clarified by (Atkinson \& Blandy, 2012), the most salient characteristic of a gated community is 'the presence of physical barriers that prevent nonresidents from entering the common areas in an estate or development that would, ordinarily, be accessible by the public'. In urban China, gated communities are characterized as 'spatial enclosures with secured gates, walls and fences, security personnel, and contracts with property management companies' ( $\underline{\mathrm{Wu}, 2005})$.

\subsection{Unfriendly social relations}

Since the role of local governments in China has experienced a great transition from traditional managerialism to entrepreneurialism, economic development is considered the top priority. The truth is that the capital from land sales for the development of private housing occupies about half of the financial resources of local government, which enables real estate developers to possess more advantage in the real estate game with their respective local governments.

Nowadays, the street office and community residents' committee is of great significance for consolidating to refurbish the functionality of local 
governments, in response to the downfall of work-units and the decline of the state's 'hierarchical' control $(\mathrm{Wu}, 2002)$. Specifically, the street office is the representative agency of district government, rather than a level of government, while the community residents' committee is merely a 'selforganized mass organization'. Nevertheless, the community residents' committee actually addresses the works assigned by the street office, including stabilizing the communities and basic welfare provision. However, the homeowners' association established in the gated community is in charge of all the issues pertinent to its own development, and its members are selected by the homeowners themselves, according to the regulation of property management. Instead of the administrative control adopted by the traditional community residents' committee, the homeowners' association, with a self-governance mode becomes more popular in the gated communities.

In the gated communities, property management companies are responsible for the provision of professional services, such as security guards, greening and the maintenance of facilities, which meets the majority of daily requirements of residents with a relatively lower payment. If residents are not satisfied with the services, the homeowners' association would be required to conduct negotiation with the property management company ( $\mathrm{Wu}, 2005)$.

The public spaces, such as the square, green space or park, provides a platform for the residents to communicate and share their interest in their spare time. For example, in the Lijiang Garden, a gated community in Southern Guangzhou, the male homeowners prefer to discuss their pets, cars and flowers in the open space, while the young female homeowners more like to discuss child-care and household affairs. The popularity of information technology products has generated more channels for residents to communicate with their neighbors more efficiently. A QQ group and WeChat group have been set up for residents to speak their own voices on the common concerns.

However, many residents do not attach great importance to the social interaction within the communities. Unlike the strict regulations on the entry to gated communities in western countries, the only eligibility criterion is affordability. Namely, residents with similar economic status have been filtered into the same gated communities, while the cultural background, occupation, educational status, religious belief and nationality are not taken into consideration. Despite social relations between residents in some gated communities maybe being positive and excellent, the neighbors have weak social cohesion (Atkinson \& Blandy, 2012). Moreover, the dwellers treat their residence as a place for living rather than as a place for social interaction $(\mathrm{Wu}, 2005)$. Thus, many residents not only have little interest in participating in the activities held within the communities, but also do not attend the election of the homeowners' association to express their opinions.

\subsection{Higher quality of living environment}

Although there are different types of gated communities for households at different income levels, the housing space is large enough for households to live in, in spite of great disparity in space standards. Each housing unit is well-designed to meet the daily requirement of consumers, which is divided into seven functional areas: entrance, living room, dining room, bedroom, kitchen, bathroom, balcony and storage space. This facilitates residents to 
achieve a high degree of self-containment and protects the privacy of house owners.

Property developers use 'packaged' community services to motivate the marketing of their properties $(\mathrm{Wu}, 2005)$, especially for the gated communities in suburban areas where municipal facilities are insufficient. For example, Country Garden of South China (Huanan Biguiyuan) labels its community services as resembling a five-star hotel, which not only stresses a high quality of physical environment, but highlights superior community facilities and services. Except for the ordinary services such as cleaning, greening, rubbish collection, security, recreation and amenities, the property developers also provide educational facilities and healthcare facilities which are usually afforded by the local governments. Even shuttle buses for the residents to travel between the communities and their workplaces are provided to solve the shortage of transportation infrastructure. Furthermore, the membership club provided by Country Garden of South China offers a broad range of sports and recreational faculties such as a gym, tennis courts, basketball courts, indoor and outdoor swimming pools, private massage rooms, aerobics studios, audio, visual theatres, and so on. All of the above signifies that many gated communities have produced self-contained habitats for the middle and upper middle income groups to enjoy their exclusive services.

\section{CONCLUSIONS}

Work-unit compounds and gated communities are the products of particular social and political context. Owing to the comprehensive nature of social sustainability, it is challenging to identify which types of housing estates are more socially sustainable. However, as elaborated above, the quality of living environments of gated communities are better than the work-unit compounds, while the social relations within the work-unit housing system are more harmonious.

Table 1. Comparison of the social sustainability of two types of housing estates

\begin{tabular}{ccc}
\hline Community type & Work-unit compound & Gated community \\
\hline Target group & Urban registered residents & Middle income or above \\
\hline Emergence time & After 1949 & After 1998 \\
\hline Provider & Government & Property developer (mainly) \\
\hline $\begin{array}{c}\text { Social } \\
\text { relationships }\end{array}$ & $\begin{array}{c}\text { Strong attachment within the } \\
\text { communities }\end{array}$ & Weaker \\
\hline $\begin{array}{c}\text { Quality of living } \\
\text { environment }\end{array}$ & Low standard, self-sustained & High quality, sometimes luxurious \\
\hline
\end{tabular}

It is revealed that the provision of work-unit housing in China, considered as an important component of socialist welfare, is fully implemented and administrated through work-units. All the work-unit compounds look quite similar, with a lack of local characteristics and environmentally friendly design. Although the concept of sustainable development was not proposed at that time, residents were obliged to live in a sustainable way, such as living in a smaller space of multi-floor walk-ups, self-contained community facilities, and so on. On the contrary, increasingly more gated communities adopted environmentally friendly design principles, with the gradual popularity of the notion of sustainable development increasing. Moreover, some luxury commodity estates even use the 
environmentally friendly design, building materials and infrastructure systems as their selling points to absorb the high-income consumers.

From the perspective of social relations, the work-unit housing provider, i.e. government, adopted a hierarchical structure to control their residents. A set of social, economic, political and spatial constraints were imposed on the daily lives of residents. In spite of this, the stronger attachment to the social networks was highly developed within the work-unit compounds, while contact with outsiders was minimized.

The rise of commodity housing compounds has changed the way in which urban communities are managed ( $\mathrm{Wu}, 2005)$. Instead of the community residents' committee and the work-unit, the homeowners' association with a self-governance mode is in charge of all the issues pertinent to the development of the gated communities. Property management companies are responsible for the provision of professional services, while traditional mutual support and assistance has disappeared. Moreover, the social cohesion of gated communities is weak, although residents select their living place intentionally.

The quality of the living environment in the work-unit compounds remained at a low living standard owing to the severe housing shortage in that era. Many households had to share kitchens, toilets and bathrooms. By contrast, there are large disparities among gated communities at different income levels. Each housing estate is well-designed to achieve a high degree of self-containment. Furthermore, the real estate developer not only stresses a high environmental quality but also highlights the provision of highquality services.

To sum up, the housing reform dramatically changed the housing supply from the government side to the market, which has undoubtedly solved the housing shortage conundrum and given rise to the improvement of living environments, and meanwhile, it also has been considered as contributing to many social problems of contemporary society, especially the weakening of social sustainability issues. Moreover, the social environment of gated communities has not been ameliorated.

\section{ACKNOWLEDGEMENT}

This research is supported by Annual Dissertation Fellowship of Peking University - Lincoln Institute (Ref. DS02-20140901-WZC).

\section{REFERENCES}

Atkinson, R., \& Blandy, S. (2012). "Gated Communities". International encyclopedia of housing and home, 232-236.

Bramley, G., \& Power, S. (2009). "Urban Form and Social Sustainability: The Role of Density and Housing Type". Environment and Planning B: Planning and Design, 36(1), 30-48.

Chen, Z., Chen, J., \& Liu, X. (2008). "The Review and Prospect of the Urban Housing Marketization Reform in China". World Economic Papers, 1, 43-45.

Chiu, R. L. (2004). "Socio-Cultural Sustainability of Housing: A Conceptual Exploration". Housing, Theory and Society, 21(2), 65-76.

City of Vancouver (CoV). (2005). "A Social Development Plan for the City of Vancouver: Moving Towards Social Sustainability, Administrative Report A7". Retrieved from Vancouver. 
Colantonio, A. (2010). "Urban Social Sustainability Themes and Assessment Methods". Proceedings of the Institution of Civil Engineers-Urban Design and Planning, 163(2), 7988.

Congreve, A. (2012). "Sustainable Communities". International encyclopedia of housing and home, 97-110.

Dempsey, N., Bramley, G., Power, S., \& Brown, C. (2011). "The Social Dimension of Sustainable Development: Defining Urban Social Sustainability". Sustainable development, 19(5), 289-300.

Gao, Y. (1990). "Propeling the Commodity Housing from Consumers". Economic Studies, 10, 64-69.

Howenstine, E. J. (1986). "The Consumer Housing Subsidy Approach Versus Producer Housing Subsidies: International Experience". Cities, 3(1), 24-40.

Huang, Y. (2005). "From Work-Unit Compounds to Gated Communities: Housing Inequality and Residential Segregation in Transitional Beijing". In Ma, L. \& Wu, F. (Eds.), Restructuring the Chinese City: Changing Society, Economy and Space. London: Routledge.

Lawhon, L. L. (2009). "The Neighborhood Unit: Physical Design or Physical Determinism?". Journal of Planning History, 8(2), 111-132.

Lee, J. (2000). "From Welfare Housing to Home Ownership: The Dilemma of China's Housing Reform". Housing Studies, 15(1), 61-76.

Logan, J. R., \& Bian, Y. (1993). "Inequalities in Access to Community Resources in a Chinese City". Social Forces, 72(2), 555-576.

Logan, R., Bian, Y., Guan, Y., Lu, H., \& Pan, Y. (1997). "“Work Units" and the Commodification of Housing: Observations on the Transition to a Market Economy with Chinese Characteristics". Social Sciences in China, 18(4), 28-35.

Ma, L. J. (2002). "Urban Transformation in China, 1949-2000: A Review and Research Agenda". Environment and planning A, 34(9), 1545-1569.

Ma, L. J., \& Wu, F. (2005). "Restructuring the Chinese City: Diverse Processes and Reconstituted Spaces". In Ma, L. J. \& Wu, F. (Eds.), Restructuring the Chinese City: Changing Society, Economy and Space (pp. 1-18). Abingdon: Routledge.

Manzi, T., Lucas, K., Jones, T. L., \& Allen, J. (2010). Social Sustainability in Urban Areas: Communities, Connectivity and the Urban Fabric: Routledge.

McKenzie, S. (2004). "Social Sustainability: Towards Some Definitions". Retrieved from Hawke Research Institute, University of South Australia.

Miao, P. (2003). "Deserted Streets in a Jammed Town: The Gated Community in Chinese Cities and Its Solution". Journal of Urban Design, 8(1), 45-66.

Office of the Deputy Prime Minister. (2006). "Uk Presidency Eu Ministerial Informal on Sustainable Communities". http://www.eukn.org/E_library/Urban_Policy/Bristol_Accord_UK_Presidency_EU_Minis terial_Informal_on_Sustainable_Communities.

Pareja-Eastaway, M. (2012). "Social Sustainability". International encyclopedia of housing and home, 502-505.

Raco, M. (2003). "Remaking Place and Securitising Space: Urban Regeneration and the Strategies, Tactics and Practices of Policing in the Uk". Urban Studies, 40(9), 1869-1887.

Wang, Y. P., \& Murie, A. (1996). "The Process of Commercialisation of Urban Housing in China". Urban Studies, 33(6), 971-989.

Wiesel, I. (2012). "Can Ageing Improve Neighbourhoods? Revisiting Neighbourhood LifeCycle Theory". Housing, Theory and Society, 29(2), 145-156.

Wu, F. (1996). "Changes in the Structure of Public Housing Provision in Urban China". Urban Studies, 33(9), 1601-1627.

Wu, F. (2002). "China's Changing Urban Governance in the Transition Towards a More Market-Oriented Economy". Urban Studies, 39(7), 1071-1093.

Wu, F. (2005). "Rediscovering the 'Gate'under Market Transition: From Work-Unit Compounds to Commodity Housing Enclaves". Housing Studies, 20(2), 235-254.

Wu, F. (2010). "Gated and Packaged Suburbia: Packaging and Branding Chinese Suburban Residential Development". Cities, 27(5), 385-396.

Ye, J.-P., Song, J.-N., \& Tian, C.-G. (2010). "An Analysis of Housing Policy During Economic Transition in China". European Journal of Housing Policy, 10(3), 273-300.

Zhang, Y., Chai, Y., \& Zhou, Q. (2009). "The Spatiality and Spatial Changes of Danwei Compound in Chinese City: Case Study of Beijing No. 2 Textile Factory". Urban Planning International, 24(5), 20-27.

Zhou, M., \& Logan, J. R. (1996). "Market Transition and the Commodification of Housing in Urban China". International Journal of Urban and Regional Research, 20(3), 400-421. 